\title{
Anorectal function and quality of life after chemoradiotherapy in patients with anal canal carcinoma
}

Francesca De Felice ${ }^{1}$, Daniela Musio ${ }^{1}$, Gloria Bernardi ${ }^{2}$, Lavinia Grapulin ${ }^{1}$, Alessio Impagnatiello ${ }^{2}$, Roberto Lisi ${ }^{1}$, Cosima Maria Moschella ${ }^{2}$, Marileda Indinnimeo ${ }^{2}$, Vincenzo Tombolini ${ }^{1,3}$

\begin{abstract}
Background A retrospective study was conducted to evaluate sphincter function and quality of life (QoL) in patients treated with radiotherapy and concurrent chemotherapy (CRT) for anal canal cancer.

Materials and Methods From 1998 to 2010, patients with anal canal cancer treated with CRT were eligible.

Radiation dose was $59.4 \mathrm{~Gy}$ ( $1.8 \mathrm{~Gy} /$ fraction) and the chemotherapy regimen was 5-fluorouracil and mitomycin

C. Anorectal function was investigated by anorectal manometry and transrectal ultrasound. QoL was assessed with the European Organization for Research and Treatment of Cancer (EORTC) QLQ-C29 questionnaire. Correlations between diagnostic parameters and patient-reported outcomes were evaluated.

Results Eighteen patients were enrolled. Overall, 4 patients had stage I disease, 8 stage II and 6 stage III. Anorectal manometry parameters were significantly lower compared to healthy scores. Patients-reported continence was significantly higher than fecal incontinence manometry scores. Ultrasound sphincter complex defects were recorded in 17 patients. Globally, a positive correlation was described between resting pressure of manometric exam and sexual functioning items and sphincter complex and patient-reported flatulence, respectively.

Conclusions Definitive CRT represents the standard of care for anal canal cancer. Patients experienced low rates of fecal incontinence compared with results of diagnostic exams. Further studies are needed to better define toxicity and QoL after definitive CRT in anal canal cancer.
\end{abstract}

Keywords: chemoradiotherapy, squamous cell carcinoma, quality of life, anorectal manometry

\section{Introduction}

The efficacy of chemoradiotherapy (CRT) as definitive treatment for anal canal cancer has been convincingly proven, due to its significantly high colostomy-free survival [1-4]. Sphincter-conserving treatment is considered as a quality of life (QoL) advantage, but CRT can be associated with chronic complications, such as fecal incontinence, that may significantly impair the patient's QoL. Advances in ionizing radiation delivery have led to increased accuracy in treatment planning, entailing less damage to critical normal tissues [5]. However, CRT still affects sphincter function, and the literature reports full sphincter function ranging from $56 \%$ to $93 \%$ [6-8]. The real role of diagnostic exam parameters on patients' QoL has not been widely examined.

Therefore, we conducted a retrospective study to evaluate anorectal function and patient QoL in order to realize if a worsening of sphincter function resulted in limitation in social life.

\section{Materials and methods}

\section{Patient population}

Of 83 patients with squamous cell carcinoma of anal canal who were treated with definitive CRT at our institution between 1998 and 2010, a statistically representative sam-

\footnotetext{
1Department of Radiotherapy, Policlinico Umberto I,

"Sapienza" University of Rome, Roma, Italy.

2Department of Surgery "P. Valdoni", Policlinico Umberto I,

"Sapienza" University of Rome, Roma, Italy.

${ }^{3}$ Spencer-Lorillard Foundation, Roma, Italy.

Correspondence to:

Francesca De Felice, MD,

Department of Radiotherapy, Policlinico Umberto I,

"Sapienza" University of Rome,

Viale Regina Elena 326, 00161 Roma, Italy.

Phone: +39 0649973411 - Fax: +390649973411

E-mail: fradefelice@hotmail.it

CANCER BREAKING NEWS 2017;5(2):33-38

DOI: $x x x x x x x x x x x x x x x x x x x$
} 
ple of 18 cases ( 14 female/4 male) were included in the study. Written informed consent was obtained from each patient following a detailed explanation of the objectives and protocol of the study which was approved by the institutional review board and the scientific review committee. Eligibility criteria included: histologically confirmed squamous cell anal canal carcinoma; non-metastatic disease at diagnosis; complete response proven by multiple biopsy at least 6 months after the end of CRT. Patients were staged based on physical examination, transrectal ultrasound and total body computed tomography (CT).

\section{Treatment plan}

All patients were treated with curative-intent treatment. RT was delivered with a 3D-conformational multiple field technique at a total dose of $45 \mathrm{~Gy}(1.8 \mathrm{~Gy} /$ fraction $)$ to the whole pelvis and an additional $14.4 \mathrm{~Gy}$ (1.8 Gy/fraction) to the primary tumor, with 6 to $15 \mathrm{MV}$ energy photons. Concomitant chemotherapy included 5-fluoruracil (1000 $\mathrm{mg} / \mathrm{m}^{2}$ by continuous infusion on days 1 to 4 and 29 to 32) plus mitomycin $\mathrm{C}\left(15 \mathrm{mg} / \mathrm{m}^{2}\right.$ intravenously on days 1 and 29).

\section{Follow-up}

Post-treatment surveillance was performed by physical examination, including digital rectal exploration and inguinal node palpation, and transrectal ultrasound every 3 months for 2 years, then every 6 months thereafter. Tumor regression was defined as the total disappearance of tumor with a normal anus mucosa within 6 months from the end of CRT. To monitor the presence of potential local recurrence and distant metastasis, total body CT was recommended annually for up 5 years after CRT.

\section{Anorectal function evaluation}

One year after treatment end, patients underwent anorectal manometry and transrectal ultrasound for investigating anorectal function. Anorectal manometry was performed using a perfused low-compliance six capillary system. The following parameters were evaluated: sphincter length (SL) in $\mathrm{cm}$, defined as the distance from the start of pressure increase to the point at which pressure drops to zero when the probe left the anal canal; resting pressure (RP) in $\mathrm{mmHg}$, defined as the highest pressure in the anal sphincter with patient relaxed; maximum squeeze pressure (MSP) in $\mathrm{mmHg}$, defined as the highest pressure rise from the RP during a voluntary contraction of the anal sphincter complex; rectal compliance (RC) in $\mathrm{mL} / \mathrm{mmHg}$, defined as the relationship between volume and pressure differences after inflation of the balloon with increasing volumes of air; relaxation of internal anal sphincter
(RIAS) in percent, defined as percentage decrease of RP on inflation of the balloon.

Transrectal ultrasound exam was performed with a 5-13 $\mathrm{MHz}$ rotary probe. In all patients the following parameters were imaged: internal anal sphincter (IAS); external anal sphincter (EAS); puborectalis muscle (PRM). Each parameter was evaluated when patients relaxed, during voluntary contraction and during attempted defecation.

\section{EORTC QLQ-CR29 questionnaire}

Patients were invited to complete a questionnaire concerning their QoL, one week before the start of therapy and three months after the treatment. The European Organization for Research and Treatment of Cancer (EORTC) QLQ-CR29 is a validated questionnaire, assessing sitespecific QoL. It comprises 38 questions, of which 19 were completed by all patients and the remaining by a subset of patients (males/females; patients with or without stoma). Patients were requested to indicate the extent to which they had experienced these symptoms or problems, answering by circling the number that best applied to them. Higher symptom scores indicated more severe symptoms.

\section{Statistical analysis}

Statistical analysis was performed using RStudio0.98.1091 software. Standard descriptive statistics were used to evaluate the distribution of each factor. Continuous data were given as median (range), and categorical data as the number of observations and ratios.

Manometric scores were compared using the MannWhitney U test. Correlations between manometric scores, parameters of transrectal echography and EORTC QLQCR29 scores were also evaluated using the Spearman test. All reported $\mathrm{p}$ values lower than 0.05 were considered statistically significant.

\section{Results}

\section{Patient characteristics}

Demographic and clinical characteristics of patients are listed in Table 1. Eight patients had stage II disease at diagnosis, whereas the remainder had stage $I(n=4)$ and stage III $(n=6)$ disease. All patients completed the programmed CRT and a clinical complete response was noted within 6 months of the end of treatment.

\section{Anorectal manometry parameters}

Anorectal manometry details are shown in Table 2. Globally, SL ( $p=0.01), \operatorname{RP}(p=0.03), \operatorname{MSP}(p=0.01), R C(p=0.02)$ and RIAS $(p=0.02)$ were significantly lower compared to healthy scores. In total, 3 patients $(16 . \%)$ were com- 
Table 1. Patient characteristics.

\begin{tabular}{lr}
\hline Characteristic & Value (\%) \\
\hline Median age, years (range) & $70(50-84)$ \\
\hline Gender, no. (\%) & $4(22.2)$ \\
\hline Male & $14(77.8)$ \\
\hline Female & \\
\hline Smoker, no. (\%) & $8(44.4)$ \\
\hline Yes & $10(55.6)$ \\
\hline No & $6(33.3)$ \\
\hline HPV status, no. (\%) & $12(66.7)$ \\
\hline Positive & $2(11.1)$ \\
\hline Negative & $8(44.4)$ \\
\hline Clinical tumor stage (T), no. (\%) & $5(27.8)$ \\
\hline T1 & $3(16.7)$ \\
\hline T2 & $4(16.7)$ \\
\hline T3 & \\
\hline T4 & \\
\hline Clinical nodal stage (N), no. (\%) & $161.1)$ \\
\hline N0 & \\
\hline N1 & \\
\hline N2 & \\
\hline
\end{tabular}

HPV: human papilloma virus

pletely incontinent, whereas 8 patients $(44.4 \%)$ had minimal leakage of stool and the remainder $(n=7,38.9 \%)$ were continent. Overall, a basal and squeeze pressure asymmetry was recorded in 12 patients $(66.7 \%)$. High asymmetry level was indicative of worse rectal compliance $(p=0.04)$. No significant difference was noted in manometric findings based on tumor stage.

\section{Transrectal echography parameters}

Transrectal echography showed defects in the sphincter

Table 2. Patients' manometry values. complex in 17 patients (94\%). Only one patient showed a normal profile. In total, 13 patients $(72.2 \%)$ had a deficit in IAS, EAS and PRM, during voluntary contraction and during attempted defecation. Whereas a PRM partial reaction and a deficit in IAS and EAS were recorded in 3 patients $(16.7 \%)$ and an isolated deficit of the sphincter complex during attempted defecation was observed in one patient $(5.6 \%)$. Matching these data with anorectal manometry results confirmed that 12 patients had a pathological value of RC.

\section{EORTC QLQ-CR29 scores}

The EORTC QLQ-CR29 questionnaire results are given in Table 3. Values analysis of frequency showed how treatment for anal canal carcinoma caused a detectable worsening of conditions, especially "unintentional release (leakage) of urine" (question 33), "pain in buttock/ anal area/rectum" (36), "dry mouth" (40), "unintentional release of gas/flatulence" (49) and "frequent bowel movements" $(52,53)$. After treatment, the most common symptom was bloated feeling in the abdomen (29\%), although evaluated as "very much" only in $6 \%$ of patients. Sixty-five percent of patients were satisfied with their body. Four patients ( 3 men/1 woman) qualified sexual dysfunction as "severe".

\section{Correlation of manometric and echographic parameters with EORTC QLQ-CR29 scores}

RP of manometric findings was positively correlated with sexual functioning items in the EORTC QLQCR29 questionnaire $(r=0.43, p=0.03)$. EORTC QLQCR29 values of completely continent patients were significantly higher than patients grouped according to fecal incontinence manometry scores. No significant difference was noted in EORTC QLQ-CR29 scores with respect to $\mathrm{RC}$ minimal balloon distention volume evok-

\begin{tabular}{|c|c|c|c|c|c|}
\hline Parameter & & Mean & Median & Min & Max \\
\hline $\mathrm{SL}$ (relaxed), cm & & 3.24 & 3.00 & 2.00 & 5.00 \\
\hline SL (voluntary contraction), cm & & 3.59 & 4.00 & 2.00 & 5.00 \\
\hline \multirow[t]{4}{*}{ Resting pressure, $\mathrm{mmHg}$} & 1 & 73.66 & 73.80 & 16.40 & 139.10 \\
\hline & 2 & 57.26 & 53.00 & 17.20 & 116.00 \\
\hline & 3 & 34.04 & 27.60 & 9.60 & 76.80 \\
\hline & 4 & 17.25 & 16.60 & 3.50 & 31.90 \\
\hline \multirow[t]{4}{*}{ Maximum squeeze pressure, $\mathrm{mmHg}$} & 1 & 162.77 & 150.00 & 32.30 & 373.40 \\
\hline & 2 & 106.37 & 108.60 & 33.00 & 234.40 \\
\hline & 3 & 86.13 & 81.90 & 39.80 & 148.30 \\
\hline & 4 & 59.09 & 55.50 & 11.80 & 173.00 \\
\hline
\end{tabular}

SL: sphincter length 
Table 3. EORTC QLQ-CR29 questionnaire.

\begin{tabular}{|c|c|c|c|c|c|c|c|c|}
\hline \multirow[b]{3}{*}{ Question } & \multicolumn{8}{|c|}{ Percent patients (no.) } \\
\hline & \multicolumn{4}{|c|}{ Before treatment } & \multicolumn{4}{|c|}{ After treatment } \\
\hline & not at all & a little & quite a bit & very much & not at all & a little & quite $\mathbf{a} b$ & very much \\
\hline 31. Did you urinate frequently during the day? & $71(12)$ & $24(4)$ & $6(1)$ & - & $47(8)$ & $24(4)$ & $24(4)$ & $6(1)$ \\
\hline $\begin{array}{l}\text { 32. Did you urinate frequently } \\
\text { during the night? }\end{array}$ & $76(13)$ & $24(4)$ & - & - & $59(10)$ & $24(4)$ & $12(2)$ & $6(1)$ \\
\hline $\begin{array}{l}\text { 33. Have you had any unintentional } \\
\text { release (leakage) of urine? }\end{array}$ & 94 (16) & - & - & $6(1)$ & $71(12)$ & $12(2)$ & $12(2)$ & $6(1)$ \\
\hline 34. Did you have pain when you urinated? & $100(17)$ & - & - & - & $94(16)$ & $6(1)$ & - & - \\
\hline 35. Did you have abdominal pain? & $94(16)$ & $6(1)$ & - & - & $71(12)$ & $18(3)$ & $12(2)$ & - \\
\hline $\begin{array}{l}\text { 36. Did you have pain in your } \\
\text { buttock/anal area/rectum? }\end{array}$ & $100(17)$ & - & - & - & $59(10)$ & $24(4)$ & $12(2)$ & $6(1)$ \\
\hline $\begin{array}{l}\text { 37. Did you have a bloated feeling } \\
\text { in your abdomen? }\end{array}$ & $76(13)$ & $18(3)$ & $6(1)$ & - & $47(8)$ & $29(5)$ & $18(3)$ & $6(1)$ \\
\hline 38. Have you had blood in your stool? & $76(13)$ & $6(1)$ & $18(3)$ & - & $94(16)$ & $6(1)$ & - & - \\
\hline 39. Have you had mucus in your stool? & $94(16)$ & - & $6(1)$ & - & $76(13)$ & $12(2)$ & $6(1)$ & $6(1)$ \\
\hline 40. Did you have a dry mouth? & $88(15)$ & $12(2)$ & - & - & $47(8)$ & $18(3)$ & $18(3)$ & $18(3)$ \\
\hline $\begin{array}{l}\text { 41. Have you lost hair as a result } \\
\text { of your treatment? }\end{array}$ & $92(12)$ & $8(1)$ & - & - & $82(14)$ & $18(3)$ & - & - \\
\hline $\begin{array}{l}42 . \text { Have you had problems with } \\
\text { your sense of taste? }\end{array}$ & $94(15)$ & $6(1)$ & - & - & $88(15)$ & - & $6(1)$ & $6(1)$ \\
\hline $\begin{array}{l}\text { 43. Were you worried about your } \\
\text { health in the future? }\end{array}$ & $88(14)$ & - & $6(1)$ & $6(1)$ & $35(6)$ & $35(6)$ & $18(3)$ & $12(2)$ \\
\hline 44. Have you worried about your weight? & $88(14)$ & $6(1)$ & - & $6(1)$ & $71(12)$ & $18(3)$ & $6(1)$ & $6(1)$ \\
\hline $\begin{array}{l}45 . \text { Have you felt physically less attractive } \\
\text { as a result of your disease or treatment? }\end{array}$ & $93(13)$ & 7 (1) & - & - & $59(10)$ & $24(4)$ & $12(2)$ & $6(1)$ \\
\hline $\begin{array}{l}\text { 46. Have you been feeling less } \\
\text { feminine/masculine as a result of your } \\
\text { disease or treatment? }\end{array}$ & $100(15)$ & - & - & - & $88(14)$ & $6(1)$ & - & $6(1)$ \\
\hline $\begin{array}{l}\text { 47. Have you been dissatisfied } \\
\text { with your body? }\end{array}$ & $93(13)$ & $7(1)$ & - & - & $67(10)$ & $7(1)$ & $13(2)$ & $13(2)$ \\
\hline $\begin{array}{l}\text { 49. Have you had unintentional } \\
\text { release of gas/flatulence from your } \\
\text { back passage? }\end{array}$ & $100(17)$ & - & - & - & $59(10)$ & $12(2)$ & $18(3)$ & $12(2)$ \\
\hline $\begin{array}{l}\text { 50. Have you had leakage of stool } \\
\text { from your back passage? }\end{array}$ & $100(17)$ & - & - & - & $63(10)$ & $31(5)$ & - & $6(1)$ \\
\hline $\begin{array}{l}51 . \text { Have you had sore skin around } \\
\text { your anal area? }\end{array}$ & $100(14)$ & - & - & - & 79 (11) & $7(1)$ & - & $14(2)$ \\
\hline $\begin{array}{l}\text { 52. Did frequent bowel movements } \\
\text { occur during the day? }\end{array}$ & $100(16)$ & - & - & - & $53(9)$ & $35(6)$ & $6(1)$ & $6(1)$ \\
\hline $\begin{array}{l}\text { 53. Did frequent bowel movements } \\
\text { occur during the night? }\end{array}$ & $100(16)$ & - & - & - & $71(12)$ & $18(3)$ & $12(2)$ & - \\
\hline $\begin{array}{l}\text { 54. Did you feel embarrassed because } \\
\text { of your bowel movement? }\end{array}$ & $100(15)$ & - & - & - & $76(13)$ & $12(2)$ & $12(2)$ & - \\
\hline $\begin{array}{l}\text { 56. (For men only) To what extent } \\
\text { were you interested in sex? }\end{array}$ & $67(2)$ & - & - & $33(1)$ & - & - & $25(1)$ & $75(3)$ \\
\hline $\begin{array}{l}\text { 57. (For men only) Did you have difficulty } \\
\text { getting or maintaining an erection? }\end{array}$ & $100(3)$ & - & - & - & - & - & $50(2)$ & $50(2)$ \\
\hline $\begin{array}{l}\text { 58. (For women only) To what extent } \\
\text { were you interested in sex? }\end{array}$ & 77 (10) & $8(1)$ & - & $15(2)$ & 85 (11) & $8(1)$ & - & $8(1)$ \\
\hline $\begin{array}{l}\text { 59. (For women only) Did you have } \\
\text { pain or discomfort during intercourse? }\end{array}$ & $100(11)$ & - & - & - & $100(11)$ & - & - & - \\
\hline
\end{tabular}

All figures were computed excluding missing data 
ing sensation to defecate. Deficit in IAS and EAS was positively correlated with flatulence $(\mathrm{r}=0.42, \mathrm{p}=0.02)$ in the EORTC QLQ-CR29.

\section{Discussion}

This retrospective study evaluated sphincter function and QoL in patients with anal canal cancer treated with definitive CRT. We analyzed anorectal function using an objective method by diagnostic exams - anorectal manometry and transrectal ultrasound - and a subjective evaluation - the EORTC QLQ-CR29 questionnaire. We observed a decrease in anal RP and a deficit in sphincter complex function. Interestingly, significant differences in term of fecal incontinence were detected in objective and subjective analysis. Most patients underestimated the sphincter damage and did not report their symptoms spontaneously, perhaps because they may consider those acceptable, as a token of survival. Despite the importance of QoL measures for appreciating patient perspectives on treatment toxicities, there have been limited studies concerning sphincter function and QoL in patients treated with CRT for anal canal cancer. Globally, published studies showed that sexual dysfunction and gastrointestinal toxicities often occurred after curative CRT [9-14]. Fecal incontinence and sexual symptoms, such as erectile dysfunction and painful sexual intercourse, were relatively common late complications experienced by patients [14-16]. These distressing symptoms have the potential to negatively influence the QoL of survivors. Recent studies showed that psychosocial QoL in anal cancer patients were worse than QoL reference values from the general population [17-18]. Most patients reported problems in work performance, daily activities and mood, increased scores for gastrointestinal symptoms and reduced sexual function.

Our results supported the data from the literature, highlighting significant long-term impairment. However, we observed that sphincter complex alteration does not significantly impact on patients' QoL. In fact, patients reported low rates of gastrointestinal discomfort compared to objective evaluation. To our knowledge, no clinical study has compared patient-reported QoL with physician reports of sphincter function experienced by anorectal manometry and transrectal ultrasound. Most of the published literature on the evaluation of toxicity and QoL in anal canal cancer patients is based on correlations with clinician-graded toxicities. Even if clinician-reported toxicities and patient-reported discomfort can be subject to bias, correlating both manometric and ultrasound parameters directly with patient-reported data remains a priority.

This study has some limitations. Firstly, the sample size was small, even though statistically representative. However, we believe it represents a significant contribution, considering that anal canal cancer is an uncommon malignancy. Moreover, this is a retrospective study. Thus the results are hypothesis-generating and should be interpreted cautiously. On the other hand, the homogeneity in treatment strategy represents the principal analysis force. Nevertheless, further clinical trials are paramount to better define toxicity and QoL after definitive CRT in patients with anal canal cancer.

\section{Conclusions}

This retrospective study demonstrated that definitive CRT is an effective conservative treatment for anal canal carcinoma. CRT may be associated with sphincter complex alteration, but provides an acceptable QoL.

\section{Acknowledgments}

The Authors thank Ray Hill, an independent medical writer, who provided native English editing and journal styling on behalf of HPS. This editorial assistance was funded by PharmaMar, Spain.

\section{Conflicts of Interest}

The Authors declare there are no conflicts of interest in relation to this article. 


\section{References}

1. Nigro ND. An evaluation of combined therapy for squamous cell cancer of the anal canal. Dis Colon Rectum 1984;27(12):763-6.

2. UKCCCR Anal Cancer Trial Working Party. Epidermoid anal cancer: results from the UKCCCR randomised trial of radiotherapy alone versus radiotherapy, 5-fluorouracil, and mitomycin. Lancet 1996;348(9034):1049-54.

3. Bartelink H, Roelofse F, Eschwege F et al. Concomitant radiotherapy and chemotherapy is superior to radiotherapy alone in the treatment of locally advanced anal cancer: results of a phase III randomized trial of the European Organization for Research and Treatment of Cancer Radiotherapy and Gastrointestinal Cooperative Groups. J Clin Oncol 1997; 15(5):2040-9.

4. Flam M, John M, Pajak TF et al. Role of mitomycin in combination with fluorouracil and radiotherapy, and of salvage chemoradiation in the definitive nonsurgical treatment of epidermoid carcinoma of the anal canal: results of a phase III randomized intergroup study. J Clin Oncol 1996;14(9):2527-39.

5. Blumetti J, Bastawrous AL. Epidermoid cancers of the anal canal: current treatment. Clin Colon Rectal Surg 2009;22(2):77-83.

6. Kapp KS, Geyer E, Gebhart FH et al. Evaluation of sphincter function after external beam irradiation and Ir192 high-dose-rate (HDR) brachytherapy \pm chemotherapy in patients with carcinoma of the anal canal [Abstract 2121]. Int J Radiat Oncol Biol Phys 1999;45(3 suppl):339.

7. Vordermark D, Sailer M, Flentje M et al. Curative-intent radiation therapy in anal carcinoma: quality of life and sphincter function. Radiother Oncol 1999;52(3):239-43.

8. Weber DC, Nouet P, Kurtz JM, Allal AS. Assessment of target dose delivery in anal cancer using in vivo thermoluminescent dosimetry. Radiother Oncol 2001;59(1):39-43.

9. Allal AS, Sprangers MAG, Laurencet F et al. Assessment of long-term quality of life in patients with anal carcinomas treated by radiotherapy with or without chemotherapy. Br J Cancer 1999;80(10):1588-94.

10. Jephcott CR, Paltiel C, Hay J. Quality of life after nonsurgical treatment of anal carcinoma: a case control study of long-term survivors. Clin Oncol (R Coll Radiol) 2004;16(8):530-5.

11. Tournier-Rangeard L, Mercier M, Peiffert D et al. Radiochemotherapy of locally advanced anal canal carcinoma: Prospective assessment of early impact on the quality of life (randomized trial ACCORD 03). Radiother Oncol 2008;87(3):391-7.

12. Das P, Cantor SB, Parker CL et al. Long-term quality of life after radiotherapy for the treatment of anal cancer. Cancer 2010;116(4):822-29.

13. Provencher S, Oehler C, Lavertu S et al. Quality of life and tumor control after short split-course chemoradiation for anal canal carcinoma. Radiat Oncol 2010;5:41.

14. Sodergren SC, Vassiliou V, Dennis K et al. Systematic review of the quality of life issues associated with anal cancer and its treatment with radiochemotherapy. Support Care Cancer 2015;23(12):3613-23.

15. Young SC, Solomon MJ, Hruby G et al. Review of 120 anal cancer patients. Colorectal Dis 2009;11(9):909-14.

16. Fakhrian K, Sauer T, Dinkel A et al. Chronic adverse events and quality of life after radiochemotherapy in anal cancer patients. A single institution experience and review of the literature. Strahlenther Onkol 2013;189(6):486-94.

17. Welzel G, Hagele V, Wenz F et al. Quality of life outcomes in patients with anal cancer after combined radiochemotherapy. Strahlenther Onkol 2011;187(3):175-82.

18. Bentzen AG, Balteskard L, Wanderas EH et al. Impaired health-related quality of life after chemoradiotherapy for anal cancer: late effects in a national cohort of 128 survivors. Acta Oncol 2013;52(4):736-44. 